\title{
Reduced expression of the claudin-7 gene correlates with venous invasion and liver metastasis in colorectal cancer
}

\author{
TAKASHI OSHIMA ${ }^{1}$, CHIKARA KUNISAKI $^{1}$, KAZUE YOSHIHARA $^{1}$, ROPPEI YAMADA $^{1}$, \\ NAOTO YAMAMOTO ${ }^{1}$, TSUTOMU SATO ${ }^{1}$, HIROCHIKA MAKINO ${ }^{1}$, SHIGERU YAMAGISHI ${ }^{1}$, \\ YASUHIKO NAGANO ${ }^{1}$, SHOICH FUJII ${ }^{1}$, MANABU SHIOZAWA ${ }^{2}$, MAKOTO AKAIKE ${ }^{2}$, \\ NOBUYUKI WADA ${ }^{3}$, YASUSHI RINO ${ }^{3}$, MUNETAKA MASUDA $^{3}$, \\ KATSUAKI TANAKA $^{1}$ and TOSHIO IMADA ${ }^{4}$
}

\begin{abstract}
${ }^{1}$ Gastroenterological Center, Yokohama City University Medical Center, 4-57 Urafune-cho, Minami-ku, Yokohama-shi, Kanagawa-ken 232-0024; ${ }^{2}$ Department of Surgery, Kanagawa Cancer Center, 1-1-2 Nakao, Asahi-ku, Yokohama-shi, Kanagawa-ken 241-0815; ${ }^{3}$ Department of first Surgery, Yokohama City University, 3-9 Fukuura, Kanazawa-ku, Yokohama-shi; ${ }^{4}$ Yokohama City University, 3-9 Fukuura, Kanazawa-ku, Yokohama-shi, Kanagawa-ken 236-0004, Japan
\end{abstract}

Received October 15, 2007; Accepted December 5, 2007

\begin{abstract}
Claudins, members of a large family of adherent junction proteins, regulate the integrity and function of tight junctions and influence tumorigenesis. Studies have suggested that altered levels of different claudins are related to carcinoma-cell invasion and disease progression. This study examined the relationship between the relative expression of claudin genes and clinicopathological factors, especially invasion and metastasis, in patients with colorectal cancer. We studied surgical specimens of cancer tissue and adjacent normal mucosa from 205 patients with untreated colorectal carcinoma. The relative expression levels of claudin-1, -3, -4 and -7 mRNA in cancer and in normal adjacent mucosa were measured by quantitative real-time, reverse-transcription polymerase chain reaction. The relative expression levels of the claudin-1,-3 and -4 genes were higher in cancer than in normal adjacent mucosa, whereas the relative expression of the claudin-7 gene was similar. An analysis of the relationship between the clinicopathological features and gene expression showed that reduced expression of claudin-7 correlated with venous invasion and liver metastasis. There was also a correlation between claudin-3 and -4 gene expression. Our results suggested that a reduced expression of the claudin-7 gene might lead to venous invasion and liver metastasis in colorectal cancer. Reduced expression of the claudin-7 gene may thus be a useful predictor of liver metastasis in patients with colorectal cancer.
\end{abstract}

Correspondence to: Dr Takashi Oshima, Gastroenterological Center, Yokohama City University Medical Center, 4-57 Urafunecho, Minami-ku, Yokohama-shi, Kanagawa-ken 232-0024, Japan E-mail: ohshimatakashi@yahoo.co.jp

Key words: claudin-1, claudin-3, claudin-4, claudin-7, colorectal cancer

\section{Introduction}

In simple epithelium, tight junctions are positioned at the boundaries of apical and basolateral plasma membranes. These junctions are thought to play an important role in the paracellular barrier and cell polarity (1-4). Several lines of evidence indicate that the granular cell layer of stratified epithelium of the skin possesses tight junctions that are crucial for barrier function $(1,2,5,6)$. The tight junctions consist of membrane and peripheral proteins. Claudins are membrane proteins composed of four transmembrane domains and two extracellular loops, through which they bind to corresponding claudins in cell-to-cell contact. Claudin-1, -3, -4 and -7 are four representative members of the 24-claudin multigene family (4), associated with cancer. An enhanced expression of claudin-1 has been reported in colorectal cancer (7). Ovarian epithelial cells that express claudin- 3 and -4 show increased invasiveness in vitro (8). Claudin-4 is a potent inhibitor of the invasiveness and phenotype of pancreatic cancer cells (9). The loss of claudin-7 expression has been observed in ductal carcinoma of the breast and squamous cell carcinoma of the head and neck $(10,11)$. Usami et al (12) reported that a reduced expression of claudin-7 correlates with tumor invasion and metastasis in squamous cell carcinoma of the esophagus. However, whether the expression of claudin-1, -3 , -4 and -7 is associated with the malignant potential of colorectal cancer remains to be clarified.

In this study, we measured the expression levels of the claudin-1, -3, - 4 and -7 genes in 205 pairs of cancer tissue and adjacent normal mucosa obtained from patients with colorectal cancer. To evaluate the clinical significance of the claudins, we examined the correlation between the relative expression of these genes and the clinicopathological features.

\section{Materials and methods}

Patients and samples. We studied surgical specimens of cancer tissue and adjacent normal mucosa obtained from 205 patients 
Table I. PCR primers and conditions.

\begin{tabular}{llcc}
\hline Gene & \multicolumn{1}{c}{ Primer } & Temperature (C) & Product size (bp) \\
\hline Claudin-1 & 5'-CCAGTTAGAAGAGGTAGTGTG-3' & 60 & 168 \\
& 5'-GAGAGGAAGGCAGTGAATC-3' & & 113 \\
Claudin-3 & 5'-ACCACCACCACCACCAAC-3' & 65 & 95 \\
Claudin-4 & 5'-GGGCTTCCTGGCTTCTGG-3' & 64.5 & 99 \\
& 5'-TGCCTTGCTCACCGAAACCC-3' & & 171 \\
S-actin & 5'-CCTCTAAACCCGTCCATCCACTC-3' & 60 & \\
& 5'-GGAGACGACAAAGTGAAGAAG-3' & 50 & \\
\hline
\end{tabular}

with untreated colorectal carcinoma. The patients underwent surgery at the Yokohama City Medical Center, Gastroenterological Center and at the Kanagawa Cancer Center between 2002 and 2006. Informed consent was obtained from each patient and the Ethics Committees of the Yokohama City Medical Center and Kanagawa Cancer Center approved the protocol before initiation of the study. Each tissue sample was embedded in O.C.T. compound (Sakura Finetechnical Co., Ltd., Tokyo) and immediately stored at $-80^{\circ} \mathrm{C}$ until use. No patient had any other malignancies. The histopathological features of specimens stained with hematoxylin and eosin were examined and sections that consisted of $>80 \%$ carcinoma cells were used to prepare total RNA.

Quantitative real-time, reverse-transcription polymerase chain reaction $(P C R)$. Total RNA isolated from colorectal cancer and adjacent normal mucosa was prepared with the use of Trizol (Gibco, Life Tech, Gaithersburg, MD). Complemetary DNA (cDNA) was synthesized from $2 \mu \mathrm{g}$ of total RNA with an iScript cDNA Synthesis kit (Bio-Rad Laboratories, Hercules, CA). After synthesis, the cDNA was diluted 1:4 with water and stored at $-20^{\circ} \mathrm{C}$ until use. Quantitative real-time PCR was performed with an iQ SYBRGreen Supermix (Bio-Rad Laboratories). PCR reactions were carried out in a total volume of $15 \mu 1$ containing cDNA derived from $75 \mathrm{ng}$ of RNA, $0.27 \mu \mathrm{M}$ of each primer, $7.5 \mu \mathrm{l}$ of iQ SYBR-Green Supermix containing dATP, dCTP, dGTP and dTTP at a concentration of $400 \mu \mathrm{M}$ each and 50 units $/ \mathrm{ml}$ of iTag DNA polymerase. The PCR consisted of $10 \mathrm{~min}$ at $94^{\circ} \mathrm{C}$, followed by 50 cycles of denaturation of the cDNA for $30 \mathrm{sec}$ at $94^{\circ} \mathrm{C}$, annealing for $30 \mathrm{sec}$ at an appropriate temperature (Table I) and a primer extension for $1 \mathrm{~min}$ at $72^{\circ} \mathrm{C}$ followed by $72^{\circ} \mathrm{C}$ for $10 \mathrm{~min}$. The PCR primer sequences of MMP2, MMP9, MT-MMP, RECK and B-actin, used as an internal control, are shown in Table I.

Statistical analysis. Gene expression levels of colorectal cancer were compared with those of normal adjacent mucosa with the use of the Wilcoxon test. The relationship between gene expression and potential explanatory variables, including age, gender, tumor size, histological type, depth of invasion, lymph node metastasis, location, lymphatic invasion, venous invasion and liver metastasis, were evaluated with the $\chi^{2}$ test.
Associations between variables were assessed using the Mann-Whitney U test. Correlation coefficients between the different variables were calculated by simple regression analysis. Each statistical analysis was performed using Statview J 5.0 software (Abacus, CA). Two-sided P-values were calculated and a difference was considered significant at $\mathrm{P}$-value $<0.05$.

\section{Results}

Comparison of claudin-1, -3, -4 and -7 mRNA expression between colorectal cancer tissue and adjacent normal mucosa. Claudin-1, -3 and -4 gene expression levels were higher in cancer than in normal adjacent mucosa $(\mathrm{P}<0.001, \mathrm{P}=0.001$ and $\mathrm{P}<0.001$ ) (Fig. 1A, B and C). The claudin-7 gene expression level of cancer did not differ significantly from that of normal adjacent mucosa ( $\mathrm{P}=0.524)$ (Fig. 1D).

Relationship of claudin-1, -3, -4 and -7 gene expression levels to clinicopathological features. Expression levels of the claudin-1, -3, -4 and -7 genes were categorized as low or high according to their median values. The relationship between the expression of these genes and clinicopathological features was then examined. The expression levels of the claudin-1, -3, -4 and -7 genes were unrelated to age, gender, tumor size, lymph node metastasis and lymphatic invasion. There were correlations between claudin-1 expression and histological type $(\mathrm{P}=0.047)$ and between claudin-4 expression and tumor location $(\mathrm{P}=0.039)$. Moreover, a reduced expression of the claudin-7 gene correlated with venous invasion $(\mathrm{P}=0.029)$ and liver metastasis $(\mathrm{P}=0.022)$ (Table II).

Associations of claudin-1, -3, -4 and -7 gene expression with lymph node metastasis in patients with colorectal cancer. There was no significant association between the expression level of any gene and the presence or absence of lymph node metastasis (Fig. 2).

Associations of claudin-1, -3, -4 and -7 gene expression with venous invasion in patients with colorectal cancer. Claudin-3 and claudin-7 gene expression levels were higher in the absence than in the presence of venous invasion $(\mathrm{P}=0.043$, $\mathrm{P}=0.001)$ (Fig. 3). 
A

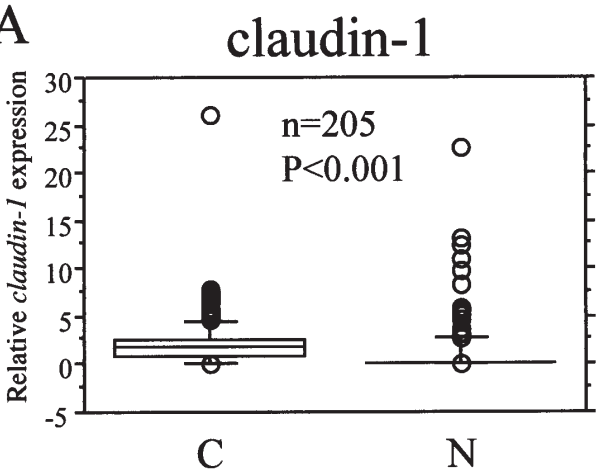

C

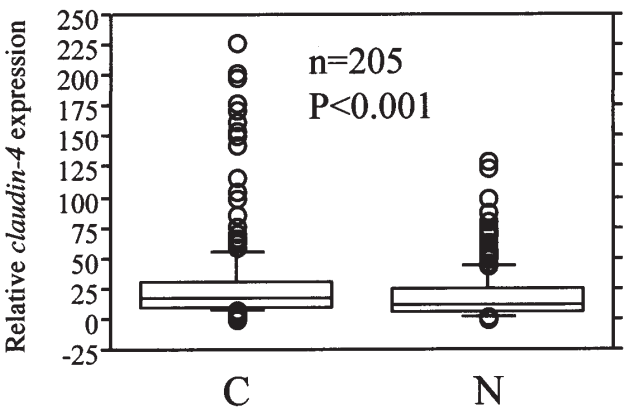

B

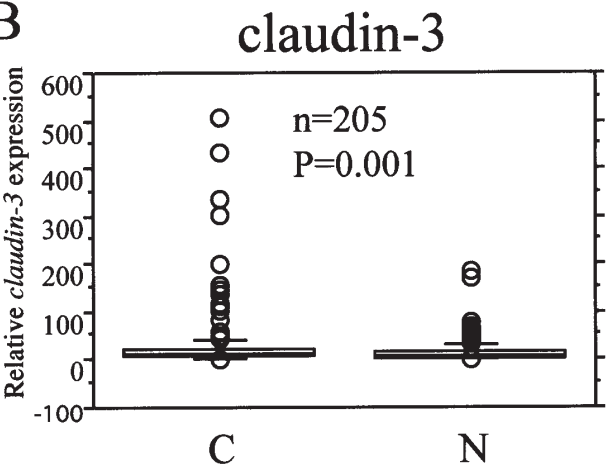

D

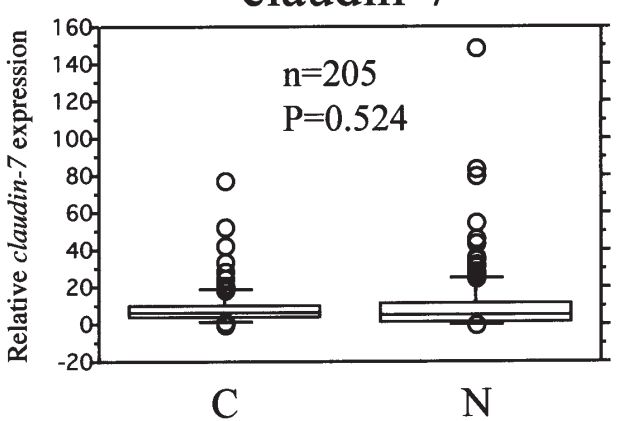

Figure 1. A comparison of claudin-1, $-3,-4$ and -7 mRNA expression levels between colorectal cancer tissue and adjacent normal mucosa. The claudin-1, -3 and -4 gene expression levels were higher in cancer than in normal adjacent mucosa $(\mathrm{P}<0.001, \mathrm{P}=0.001, \mathrm{P}<0.001)$. Claudin-7 gene expression levels did not differ significantly between cancer and normal adjacent mucosa.

\section{A}

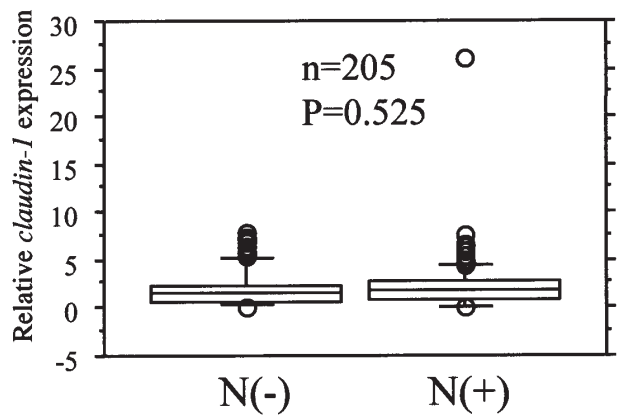

C

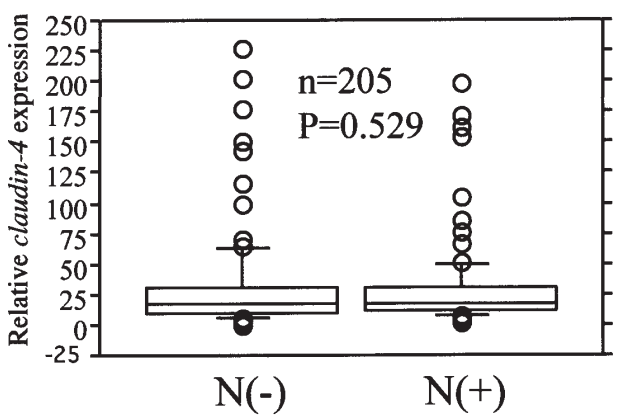

B

claudin-3

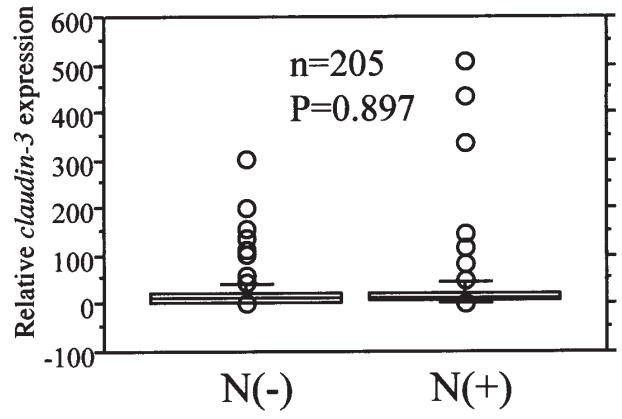

D claudin-7

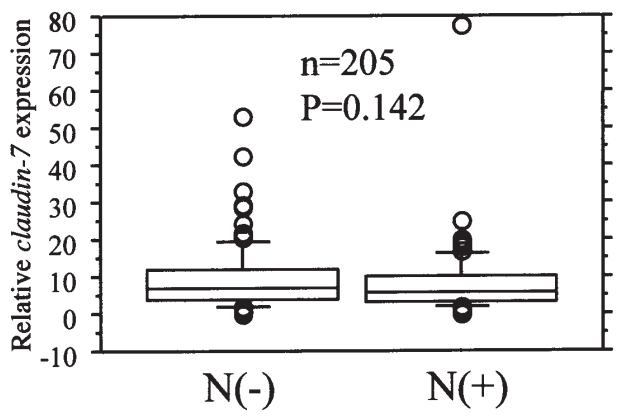

Figure 2. Associations of claudin-1,-3, -4 and -7 gene expression with lymph node metastasis in 205 patients with colorectal cancer. Box boundaries, the 25th and 75th percentiles of the observed values; capped bars, the 10th and 90th percentiles; solid line, median. P-values were calculated by the Mann-Whitney U test. The expression level of none of the genes examined correlated with the presence or absence of lymph node metastasis. 


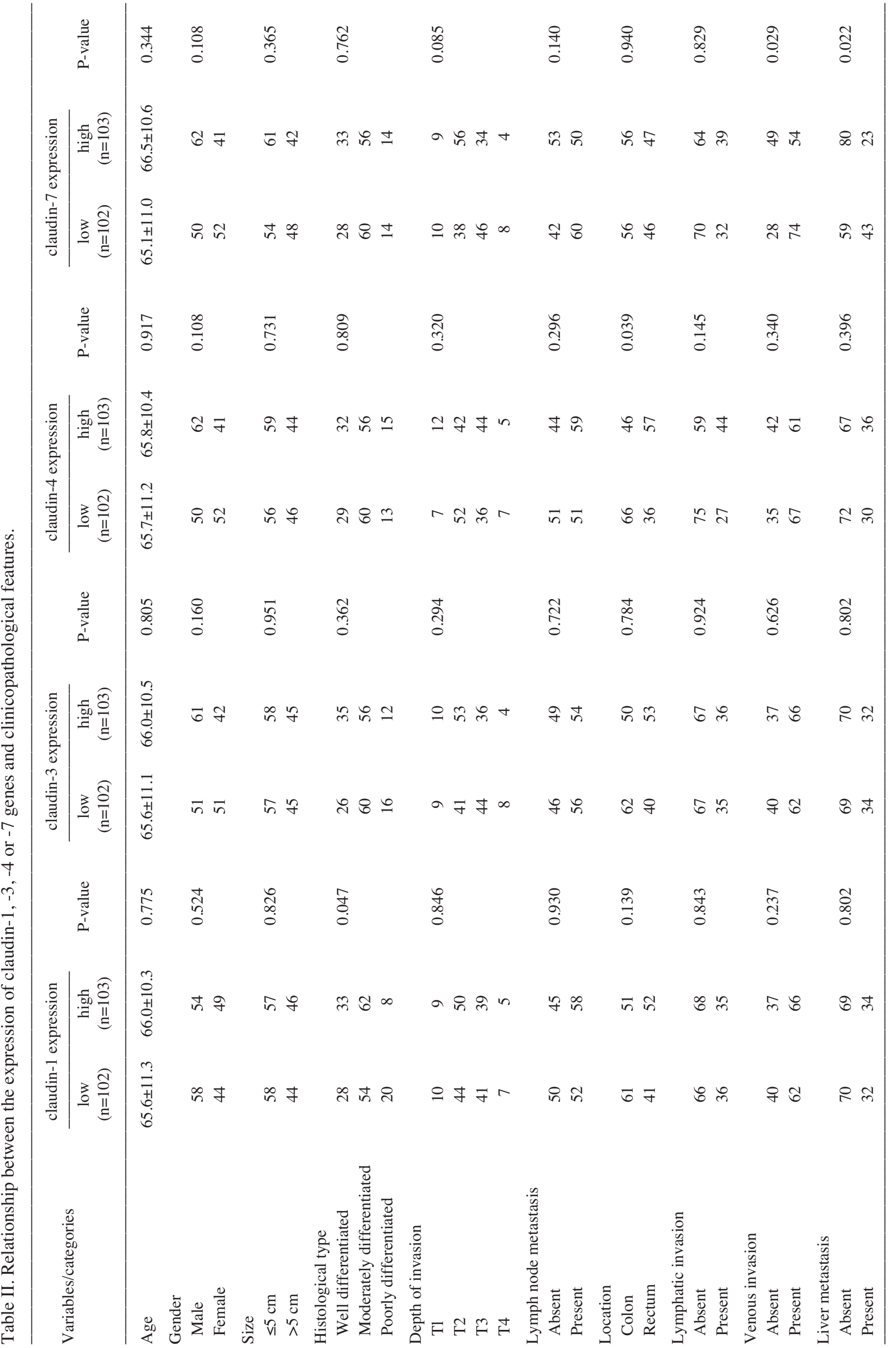


A

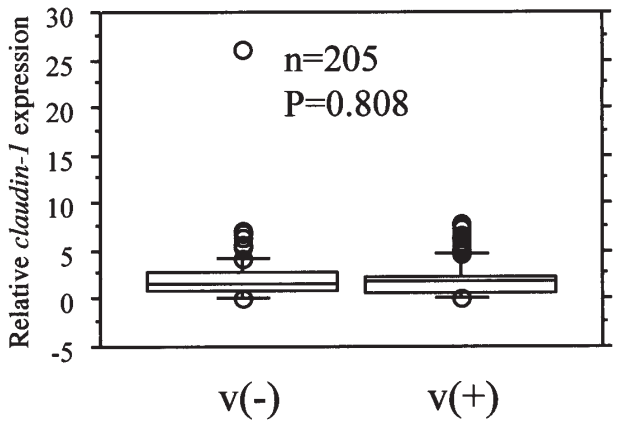

C

claudin-4

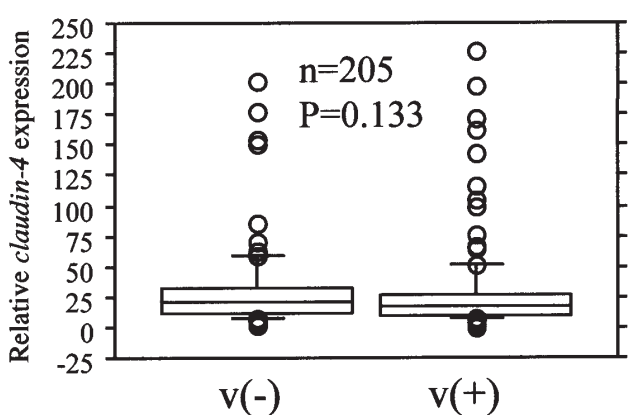

B

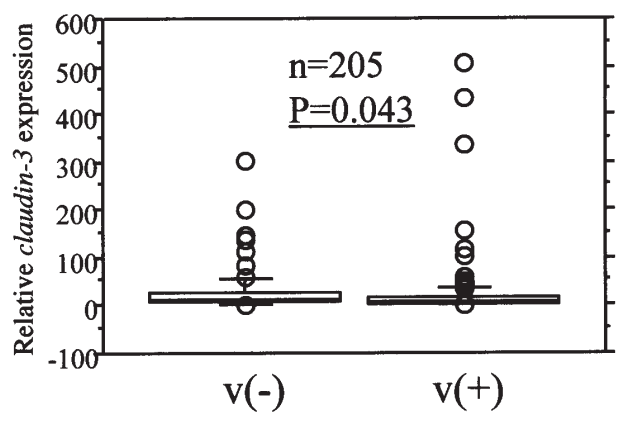

D claudin-7

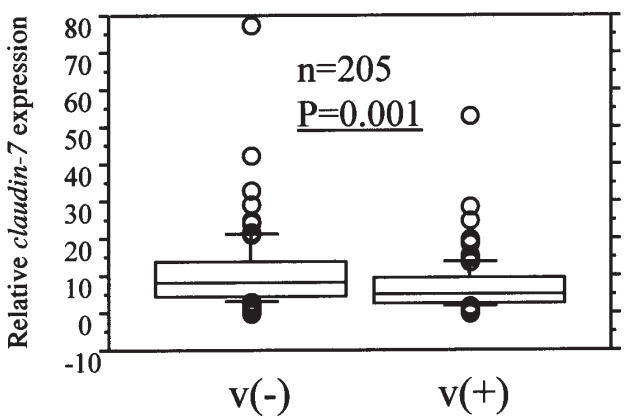

Figure 3. Associations of claudin-1, -3, -4 and -7 gene expression levels with venous invasion in 205 patients with colorectal cancer. Box boundaries, the 25th and 75th percentiles of the observed values; capped bars, the 10th and 90th percentiles; solid line, median. P-values were calculated by the Mann-Whitney U test. Claudin-3 and -7 gene expression levels were higher in the absence than in the presence of venous invasion $(\mathrm{P}=0.043, \mathrm{P}=0.001)$.

A

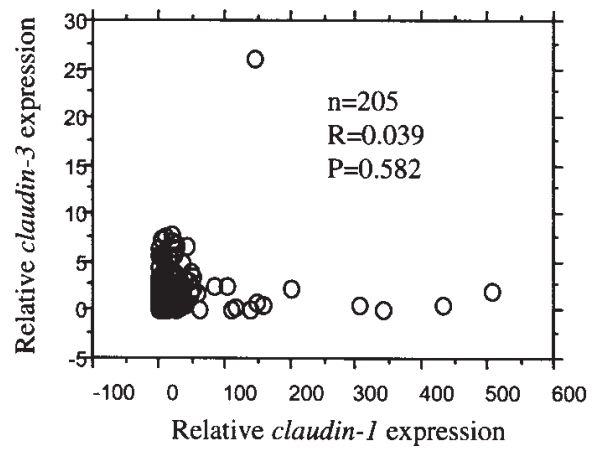

D

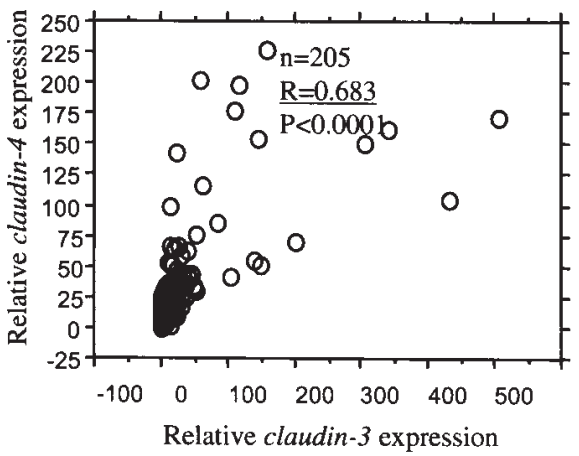

B

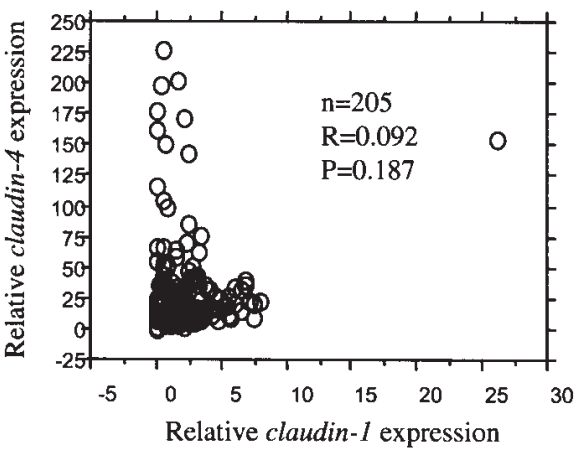

$\mathrm{E}$

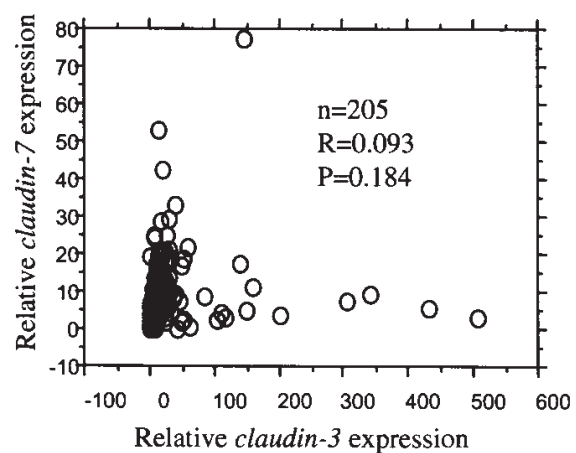

C

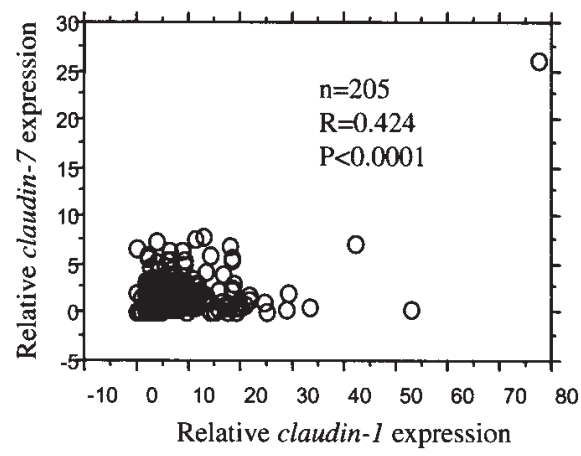

F

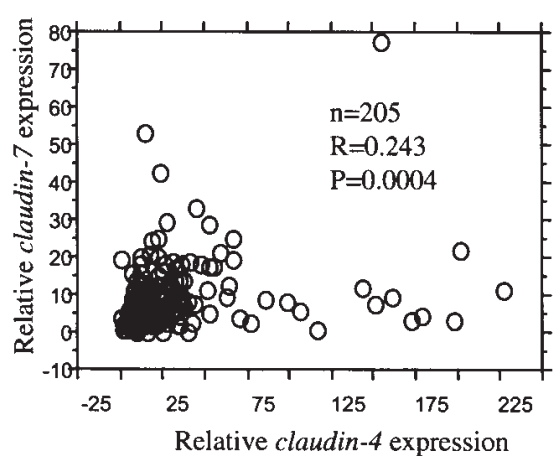

Figure 4. Correlation among claudin-1,-3,-4 and -7 gene expression levels in colorectal cancers. Each gene expression level is relative to that of the $\beta$-actin gene. The expression of the claudin-3 gene correlated with that of the claudin- 4 gene $(\mathrm{R}=0.683)$. 
Correlations among claudin-1, -3, -4 and -7 gene expression. Correlations between gene expression levels are shown in Fig. 4. The expression of the claudin-3 gene correlated with that of the claudin-4 gene $(\mathrm{R}=0.683)$.

\section{Discussion}

Cell-to-cell adhesiveness is generally reduced in various human cancers. The dissociation of cancer cells from primary cancer nests is a crucial step in metastasis. The suppression of cell-to-cell adhesiveness may trigger the release of cancer cells from primary cancer nests and increase tumor invasiveness (13). In this study, we examined the expression levels of the claudin-1, -3, -4 and -7 genes in colorectal cancer and the relationship of such levels to clinicopathological variables.

We compared the mRNA expression of each claudin gene between colorectal cancer tissue and adjacent normal mucosa. Dhawan et al (14) reported that the expression of claudin-1 is higher in human primary colon carcinoma and metastasis than in normal colorectal tissue. Pan et al (15) found that the expression of claudin- 3 and -4 is significantly higher in human endometrial carcinoma than in normal endometrial tissue at the protein and mRNA levels. As for claudin-7, Kominsky et al (10) reported that this gene is down-regulated in breast cancers as compared with normal breast tissue. However, Sobel et al (16) found no significant difference in the expression of claudin-7 between human invasive cervical carcinoma and normal cervical tissue. In our study, expression levels of the claudin-1,-3 and -4 genes were higher in cancer than in normal adjacent mucosa, whereas the expression level of the claudin-7 gene cancer did not differ significantly between cancer and normal adjacent mucosa.

We then examined the relationship between claudin gene expression levels and clinicopathological features. Sheehan et al (17) reported that a decreased expression of claudin-1 correlates with high tumor grade and biochemical disease recurrence in prostate carcinomas. Resnick et al (18) showed that a low expression level of claudin-1 is associated with a higher tumor grade and recurrence in patients with colorectal cancer. In our study, claudin-1 expression was associated with the histological type. As for claudin-3 and -4, Sheehan et al (17) reported that the expression of claudin-3 correlates with advanced-stage tumors and recurrence, whereas the expression of claudin- 4 correlates with only advanced-stage tumors. Pan et al (15) found a slight though insignificant trend towards positive associations of claudin-3 and -4 levels with tumor grade and disease stage in patients with endometrial carcinoma. Our study found no significant relationship between the expression level of the claudin-3 gene and any clinicopathological feature. The expression of the claudin-4 gene correlated with only tumor location. As for claudin-7, Kominsky et al (10) reported that the loss of claudin-7 expression is associated with nodal metastasis in primary breast carcinomas. Sauer et al (19) found that a reduced expression of claudin-7 correlates with metastatic disease in breast carcinoma. Usami et al (12) demonstrated that a reduced expression of claudin-7 correlates with metastasis in squamous cell carcinoma of the esophagus. In our study, a reduced expression of the claudin-7 gene correlated with venous invasion and liver metastasis in colorectal cancer.

When expression levels of the claudin-1, -3, -4 and -7 genes were contrasted with the presence or absence of lymph node metastasis, no correlation was noted for any gene. We also examined potential correlations of gene expression levels with the presence or absence of venous invasion. Sauer et al (19) reported that a reduced expression of claudin-7 correlates with metastatic disease. Usami et al (12) found that a reduced expression of claudin-7 correlates with tumor invasion in squamous cell carcinoma of the esophagus. In our study, claudin-3 and -7 gene expression levels were higher in the absence than in the presence of venous invasion. This finding suggested that reduced claudin-3 or -7 gene expression levels might contribute to venous invasion in colorectal cancer.

We then examined correlations among claudin-1, -3, -4 and -7 gene expression in colorectal cancers. Expression of the claudin-3 gene was found to correlate with that of the claudin-4 gene.

In conclusion, our results show that a reduced expression of the claudin-7 gene correlates with venous invasion and liver metastasis in colorectal cancer. Reduced levels or the absence of claudin-7 expression may thus be a novel marker or predictor of metastasis.

\section{References}

1. Tsukita S and Furuse M: Claudin-based barrier in simple and stratified cellular sheets. Curr Opin Cell Biol 14: 531-536, 2002.

2. Furuse M, Hata M, Furuse K, Yoshida Y, Haratake A, Sugitani Y, Noda T, Kubo A and Tsukita S: Claudin-based tight junctions are crucial for the mammalian epidermal barrier: a lesson from claudin-1-deficient mice. J Cell Biol 156: 1099-111, 2002.

3. Eaton S and Simons K: Apical, basal, and lateral cues for epithelial polarization. Cell 82: 5-8, 1995.

4. Tsukita S, Furuse M and Itoh M: Multifunctional strands in tight junctions. Nat Rev Mol Cell Biol 2: 285-293, 2001

5. Morita K, Tsukita S and Miyachi Y: Tight junction-associated proteins (occludin, ZO-1, claudin-1, claudin-4) in squamous cell carcinoma and Bowen's disease. Br J Dermatol 151: 328-334, 2004.

6. Morita K, Furuse M, Fujimoto K and Tsukita S: Claudin multigene family encoding four-transmembrane domain protein components of tight junction strands. Proc Natl Acad Sci USA 96: 511-516, 1999.

7. Miwa N, Furuse M, Tsukita S, Niikawa N, Nakamura Y and Furukawa Y: Involvement of claudin-1 in the beta-catenin/Tcf signaling pathway and its frequent upregulation in human colorectal cancers. Oncol Res 12: 469-476, 2001.

8. Agarwal R, D'Souza T and Morin PJ: Claudin-3 and claudin-4 expression in ovarian epithelial cells enhances invasion and is associated with increased matrix metalloproteinase-2 activity. Cancer Res 65: 7378-7385, 2005.

9. Michl P, Barth C, Buchholz M, Lerch MM, Rolke M, Holzmann KH, Menke A, Fensterer H, Giehl K, Löhr M, Leder G, Iwamura T, Adler G and Gress TM: Claudin-4 expression decreases invasiveness and metastatic potential of pancreatic cancer. Cancer Res 63: 6265-6271, 2003.

10. Kominsky SL, Argani P, Korz D, Evron E, Raman V, Garrett E, Rein A, Sauter G, Kallioniemi OP and Sukumar S: Loss of the tight junction protein claudin-7 correlates with histological grade in both ductal carcinoma in situ and invasive ductal carcinoma of the breast. Oncogene 22: 2021-2033, 2003.

11. Al Moustafa AE, Alaoui-Jamali MA, Batist G, Hernandez-Perez M, Serruya C, Alpert L, Black MJ, Sladek R and Foulkes WD: Identification of genes associated with head and neck carcinogenesis by cDNA microarray comparison between matched primary normal epithelial and squamous carcinoma cells. Oncogene 21: 2634-2640, 2002.

12. Usami Y, Chiba H, Nakayama F, Ueda J, Matsuda Y, Sawada N, Komori T, Ito A and Yokozaki H: Reduced expression of claudin-7 correlates with invasion and metastasis in squamous cell carcinoma of the esophagus. Hum Pathol 37: 569-577, 2006. 
13. Hirohashi S: Inactivation of the E-cadherin-mediated cell adhesion system in human cancers. Am J Pathol 153: 333-339, 1998.

14. Dhawan P, Singh AB, Deane NG, No Y, Shiou SR, Schmidt C, Neff J, Washington MK and Beauchamp RD: Claudin-1 regulates cellular transformation and metastatic behavior in colon cancer. $\mathrm{J}$ Clin Invest 115: 1765-1776, 2005.

15. Pan XY, Wang B, Che YC, Weng ZP, Dai HY and Peng W: Expression of claudin-3 and claudin-4 in normal, hyperplastic, and malignant endometrial tissue. Int J Gynecol Cancer 17: 233-241, 2007.

16. Sobel G, Páska C, Szabó I, Kiss A, Kádár A and Schaff Z: Increased expression of claudins in cervical squamous intraepithelial neoplasia and invasive carcinoma. Hum Pathol 36: 162-169, 2005.
17. Sheehan GM, Kallakury BV, Sheehan CE, Fisher HA, Kaufman RP Jr and Ross JS: Loss of claudins- 1 and -7 and expression of claudins-3 and -4 correlate with prognostic variables in prostatic adenocarcinomas. Hum Pathol 38: 564-569, 2007.

18. Resnick MB, Gavilanez M, Newton E, Konkin T, Bhattacharya B, Britt DE, Sabo E and Moss SF: Claudin expression in gastric adenocarcinomas: a tissue microarray study with prognostic correlation. Hum Pathol 36: 886-892, 2005.

19. Sauer T, Pedersen MK, Ebeltoft K and Naess O: Reduced expression of claudin-7 in fine needle aspirates from breast carcinomas correlate with grading and metastatic disease. Cytopathology 16: 193-198, 2005. 